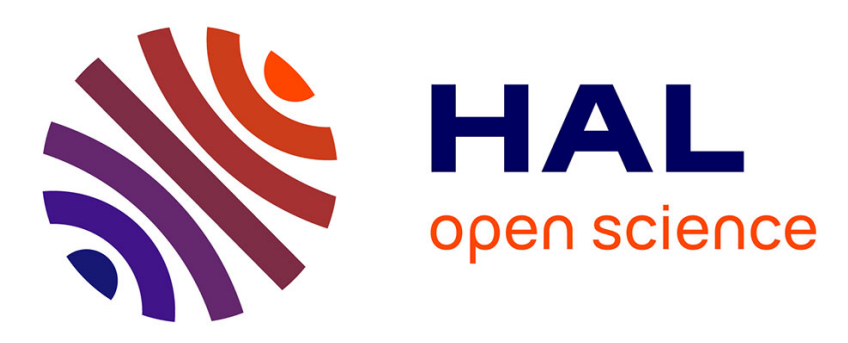

\title{
Acute metabolic responses after continuous or interval exercise in post-menopausal women with overweight or obesity
}

Marine Dupuit, Audrey Boscaro, Alban Bonnet, Patrice Bouillon, Bruno

Pereira, Claire Morel, Mélanie Rance, Nathalie Boisseau

\section{To cite this version:}

Marine Dupuit, Audrey Boscaro, Alban Bonnet, Patrice Bouillon, Bruno Pereira, et al.. Acute metabolic responses after continuous or interval exercise in post-menopausal women with overweight or obesity. Scandinavian Journal of Medicine and Science in Sports, 2020, 30 (12), pp.2352-2363. 10.1111/sms.13814. hal-02992009

\section{HAL Id: hal-02992009 \\ https://hal.science/hal-02992009}

Submitted on 17 Nov 2021

HAL is a multi-disciplinary open access archive for the deposit and dissemination of scientific research documents, whether they are published or not. The documents may come from teaching and research institutions in France or abroad, or from public or private research centers.
L'archive ouverte pluridisciplinaire HAL, est destinée au dépôt et à la diffusion de documents scientifiques de niveau recherche, publiés ou non, émanant des établissements d'enseignement et de recherche français ou étrangers, des laboratoires publics ou privés. 


\section{Acute metabolic responses after continuous or interval exercise in postmenopausal women with overweight or obesity.}

Marine Dupuit ${ }^{1}$, Audrey Boscaro ${ }^{1}$, Alban Bonnet ${ }^{1}$, Patrice Bouillon ${ }^{2}$, Bruno Pereira ${ }^{3}$, Claire Morel $^{4}$, Mélanie Rance ${ }^{4}$, Nathalie Boisseau ${ }^{1}$.

${ }^{1}$ Laboratory of Metabolic Adaptations to Exercise under Physiological and Pathological conditions (AME2P), University Clermont Auvergne (UCA), EA 3533, Clermont-Ferrand, France.

marine.dupuit@uca.fr; audreybos@orange.fr; albanbonnet9@gmail.com;

$\underline{\text { nathalie.boisseau@uca.fr }}$

2: Department of Cardiology, Vichy Hospital, 03300 Vichy, France.

patrice.bouillon@ch-vichy.fr

${ }^{3}$ : Biostatistics Unit (DRCI), Clermont-Ferrand University Hospital, Clermont-Ferrand, France

4: Centre of Resources, Expertise and Performance in Sports (CREPS), 03321 Bellerive-surAllier, France.

melanie.rance@creps-vichy.sports.gouv.fr; claire.morel@creps-vichy.sports.gouv.fr

\section{Corresponding author}

\section{Professor Nathalie Boisseau (PhD).}

Laboratoire des Adaptations Métaboliques à l'Exercice en conditions Physiologiques et Pathologiques (AME2P), 3 rue de la Chebarde, 63171, Aubière Cedex, France.

Phone number: 00334734055 19;

nathalie.boisseau@uca.fr 



\section{Abstract}

Purpose: This study compared the effects of acute HIIE and MICE on post-exercise $\mathrm{VO}_{2}$, fat utilization, and 24h-energy balance for a better understanding of the higher fat mass reduction observed after high-intensity interval training in postmenopausal women with overweight/obesity.

Methods: 12 fasted women (59.5 \pm 5.8 years; BMI: $28.9 \pm 3.9$ kg.m ${ }^{-2}$ ) completed three isoenergetic cycling exercise sessions in a counterbalanced, randomized order: i) MICE [35min at $60-65 \%$ of peak heart rate, $\mathrm{HR}_{\max }$, ii) HIIE 1 [ $60 \times(8$ s cycling-12s recovery) at $80-90 \%$ of $\left.\mathrm{HR}_{\max }\right]$ and iii) $\mathrm{HIIE} 2$ [10 $\times 1$ min at $80-90 \%$ of $\mathrm{HR}_{\max }-1$ min recovery]. The three modalities were compared for $\mathrm{VO}_{2}$ and fat utilization measured at rest and during the $2 \mathrm{~h}$ post-exercise, enjoyment, perceived exertion and appetite recorded during the session and energy intake (EI) and energy expenditure (EE) assessed over the next $24 \mathrm{~h}$.

Results: Overall fat utilization increased after exercise. No modality effect or time-modality interaction were observed concerning $\mathrm{VO}_{2}$ and fat oxidation rate during the $2 \mathrm{~h}$ post-exercise. The two exercise modalities did not induce specific EI and EE adaptations, but perceived appetite scores at 1 h post-exercise were lower after HIIE $1 \& 2$ than MICE. Perceived exertion was higher during HIIE $1 \& 2$ than MICE, but enjoyment did not differ among modalities.

Conclusion: The acute HIIE responses did not allow us to explain the greater fat mass loss observed after regular high-intensity interval training in postmenopausal women with overweight/obesity. More studies are therefore necessary to understand the mechanisms involved in such adaptations.

$\underline{\text { Key words: }}$ Postmenopausal women, exercise modalities, oxygen consumption, lipid utilization, appetite, energy balance, exertion, enjoyment. 


\section{Introduction}

Menopause is associated with body fat distribution changes, leading to abdominal fat mass accumulation, which partly explains the higher incidence of obesity and type 2 diabetes in this population ${ }^{1}$. Moroever, menopause is also related to a lower resting metabolic rate (RMR), a decrease of total energy expenditure (TEE), and a reduction of fat oxidation during moderateintensity prolonged exercise ${ }^{2,3}$. These adaptations are partly explained by the loss of fat-free mass with age and the gradual decrease of oestrogen concentration ${ }^{2,3}$. As oestrogen deficiency also stimulates appetite ${ }^{4}$, menopause favours weight and fat mass gain, hypercholesterolemia, and hypertension, thus increasing the risk of cardiovascular diseases ${ }^{1}$.

Regular physical activity may be an efficient strategy to counteract the menopause-related body composition changes ${ }^{5}$. Moderate-intensity continuous training (MICT) is traditionally recommended in patients with obesity for losing weight and fat mass ${ }^{6}$. This modality is efficient in pre- and postmenopausal women who are overweight or obese ${ }^{7,8}$, but the volume of training needed to observe body composition changes makes sometimes the long-term exercise adherence difficult. Currently, high-intensity interval training (HIIT), which includes repeated bouts of high-intensity effort followed by varied recovery times, is considered a time-efficient and safe strategy to reduce total fat mass, and particularly abdominal/visceral fat mass ${ }^{9}$, also in postmenopausal women ${ }^{10-12}$. Although studies are still required to determine the best HIIT protocols for fat mass reduction in function of the subject's characteristics, meta-analyses suggest that despite the higher rate of perceived exertion (RPE) during exercise, HIIT is more enjoyable that MICT and this could favour better adherence ${ }^{13}$. However, this conclusion has not been validated in postmenopausal women in whom breath shortness, leg pain, and perhaps fatigue during HIIT could make this modality less tolerable ${ }^{13}$. 
In addition, the mechanisms underlying larger total and (intra)-abdominal fat mass loss in HIIT are not completely elucidated, but might partly be the result of increased catecholamine production, leading to significant lipolysis during exercise, followed by higher post-exercise fat oxidation $\left(\mathrm{FAT}_{\theta \mathrm{x}}\right)^{9}$. These adaptations are probably facilitated by the higher excess postexercise oxygen consumption (EPOC) generally observed after exercise performed above $75 \%$ of the maximal oxygen uptake $\left(\mathrm{VO}_{2 \max }\right)^{14,15}$. Moreover, a decrease of post-exercise appetite could also contribute to the larger fat mass loss ${ }^{9}$. Indeed, acute high-intensity intermittent exercise (HIIE) may stimulate anorexigenic signals that could limit energy intake (EI) for few hours ${ }^{16}$. However, the decreased oestrogen and possibly also the reduced melatonin production associated with depressed mood sometimes reported during menopause could affect the anorexigenic/orexigenic signal ratio ${ }^{4}$. Furthermore, food overcompensation over $24 \mathrm{~h}$ could mask HIIE short-term anorexigenic effect.

Therefore, the aim of this study was to compare oxygen consumption $\left(\mathrm{VO}_{2}\right)$ during the $2 \mathrm{~h}$ postexercise, fat utilization, and perceived appetite, as well as the $24 \mathrm{~h}$ post-exercise energy balance of three different isoenergetic exercise modalities: one cycling moderate-intensity continuous exercise (MICE), and two high-intensity intermittent exercises (HIIE 1 \& HIIE 2). Enjoyment and perceived exertion RPE were also recorded in view of long-term exercise adherence.

We hypothesized that compared with the traditional MICE, i) HIIE would lead to higher postexercise $\mathrm{VO}_{2}$ and fat utilization (more significant for HIIE 2 that has a longer active phase performed at the same intensity), ii) the two HIIE sessions would be more enjoyable despite the greater intensity; and that overall the three sessions would lead to similar $24 \mathrm{~h}$ post-exercise energy balance, despite the lower post-exercise perceived appetite scores in HIIE. 


\section{Methods}

This study was approved by the Institutional Ethics Review Board (number: IRB000124762020-24-03-50) and was performed in conformity with the policy statement on the use of human subjects outlined in the sixth Declaration of Helsinki. The protocol was registered at ClinicalTrails.gov via the Protocol Registration System (number: NCT04364061). This protocol was proposed within the usual care framework for menopausal women with overweight/obesity at the CREPS Auvergne Rhône-Alpes in Vichy, France. All women underwent first a medical examination (pre-participation health screening performed by a sports physician). After receiving detailed information on the study objectives and protocol, each participant signed a written informed consent.

\section{Participants}

15 women with overweight or obesity (mean age: $60.5 \pm 5.8$ years) were first recruited. Inclusion criteria were: postmenopausal women (menopause defined as spontaneous amenorrhea for at least 12 months) and body mass index (BMI) $>25 \mathrm{~kg} \cdot \mathrm{m}^{-2}$ and $\leq 40 \mathrm{~kg} \cdot \mathrm{m}^{-2}$. Non-inclusion criteria were: medical contraindications to intense physical activity, painful joints, and taking hormone replacement therapy. None of the participants had history of chronic arterial or respiratory disease, $\mathrm{EVD}$ cardiovascular diseases or any endocrine disorder. None of them took any medication. Three patients had to stop the study due to Covid-19 -related lockdown policies, and only 12 participants could finish the protocol. No participant had history of chronic arterial or respiratory diseases, cardiovascular diseases, or endocrine disorders. All participants had low levels of physical activity, based on the Global Physical Activity Questionnaire (GPAQ) results ${ }^{17}$. 
Anthropometric and body composition measurements.

Body weight was measured to the nearest $0.1 \mathrm{~kg}$ on a Seca709 scale (Balance Seca 709, France) in fasting conditions, with subjects wearing only underwear. Height was measured to the nearest $0.5 \mathrm{~cm}$ with a wall-mounted stadiometer. BMI Body mass index was calculated as body weight $(\mathrm{kg})$ divided by the square of height $\left(\mathrm{m}^{2}\right)$. Waist circumference $(\mathrm{cm})$ was measured midway between the last rib and upper iliac crest $(\mathrm{cm})$ in standing position with a measuring tape. The fat percentage was determined in fasting conditions, with an empty bladder, using the impedance technique (Tanita TBF-300, Netherlands), according to the manufacturer's instructions.

\section{Exercise sessions}

Each participant took part in three exercise sessions (one MICE and two HIIE) (Fig. 1). The three modalities were tested in a randomized counterbalanced design with a 6-8-day interval between sessions for perfect recovery. Subjects were instructed to eat the same dinner at the same hour the evening before each session, to refrain from any vigorous exercise $48 \mathrm{~h}$ before each session, and to avoid coffee, alcohol and tobacco.

The three exercise sessions were isoenergetic. To this aim, before the beginning of the protocol, the energy expenditure (EE) induced by HIIE 1 was measured (Metamax 3B apparatus; Matsport, France) in four postmenopausal women with obesity/overweight not included in the protocol. Then, the time needed to obtain the same EE was calculated for MICE and HIIE 2. The mean EE for each session was $182 \pm 26 \mathrm{kcal}$ and was obtained by a 35 -min MICE session and ten repetitions for HIIE 2.

All three exercise sessions were carried out on a WattBike pro Concept2 (with a freewheel and a double air and magnetic braking system) and included 5-min warm-up and 2-min cool-down on the bike at a workload chosen by the participant. 
The three modalities were:

HIIE 1: this modality was based on the protocol described by Dupuit et al. ${ }^{10}$ and consisted of 60 cycles of sprinting/speeding for $8 \mathrm{~s}$ followed by slow pedalling (20-30 rpm) for $12 \mathrm{~s}$. Resistance was very low to facilitate acceleration and limit the bicycle-wheel inertia. Resistance was set to reach $80-90 \%$ of the subjects' maximal heart rate $\left(\mathrm{HR}_{\max }\right)$ during the active phase.

HIIE 2: consisted of ten 1-min bouts at $80-90 \% \mathrm{HR}_{\max }$, separated by ten 1-min recovery bouts (i.e. slow pedalling at $20-30 \mathrm{rpm}$ ).

MICE: consisted in cycling for $35 \mathrm{~min}$ at $60-65 \% \mathrm{HR}_{\max }$. Each participant's resistance and pedal cadence $(50-70 \mathrm{rpm})$ were controlled to reach the expected intensity.

$\mathrm{HR}_{\max }$ was estimated using the Tanaka's formula ${ }^{18}(\mathrm{HRmax}=208-(0.7 *$ age $)$.

\section{Experimental Design (Fig. 2)}

Upon arrival at 7:00 AM, participants had been fasting from at least 10 hours. After recording the perceived appetite and measuring fasting glycaemia with an Accu-Chek meter (see below), subjects rested in a comfortable chair for $10 \mathrm{~min}$. Then, gas exchanges $\left(\mathrm{VO}_{2}\right.$ and $\left.\mathrm{VCO}_{2}\right)$ were measured after adaptation to the face mask for $15 \mathrm{~min}$. Afterwards, participants were placed on a cycle ergometer for the exercise session. Heart rate was continuously monitored during the exercise (Polar, A360). RPE- Perceived exertion, perceived appetite, physical activity enjoyment scale (PACES), and glycaemia were recorded or measured during the exercise and the $2 \mathrm{~h}$ recovery period (Fig. 2). Immediately post-exercise (IP), subjects drank some water and were instructed to sit quietly to watch TV for 2 hours during which gas exchanges were measured. After this period, subjects consumed a standard breakfast before leaving. At home, participants completed a $24 \mathrm{~h}$ food-intake questionnaire and a physical activity questionnaire (up to the end of breakfast the following day). 


\section{$\underline{\text { Indirect calorimetry }}$}

The experiment was performed in a ventilated room at a temperature of $19^{\circ} \mathrm{C}-20^{\circ} \mathrm{C}$. RMR and substrate utilization were determined from respiratory gases $\left(\mathrm{VO}_{2}\right.$ and $\left.\mathrm{VCO}_{2}\right)$ using a Metamax 3B apparatus (Matsport, France). Carbohydrate oxidation $\left(\mathrm{CHO}_{\mathrm{ox}}\right)$ and fat oxidation $\left(\mathrm{FAT}_{\mathrm{ox}}\right)$ were measured from the respiratory exchange ratio $\left(\mathrm{RER}=\mathrm{VCO} / \mathrm{VO}_{2}\right)$ at rest before exercise, and during the $2 \mathrm{~h}$ recovery period (Fig. 2). RMR assessment was considered valid in the presence of a minimum of $10 \mathrm{~min}$ of steady state with less than $10 \%$ of $\mathrm{VO}_{2}$ fluctuations. RMR $\left(\mathrm{kcal}^{-1} \mathrm{~d}^{-1}\right.$ was calculated using the Weir equation, and $\mathrm{CHO}_{\mathrm{ox}}$ and $\mathrm{FAT}_{\mathrm{ox}}\left(\mathrm{g}_{\mathrm{g}} \mathrm{min}^{-1}\right)$ were calculated using the Perronet and Massicotte equations, as follows ${ }^{19}$ :

$\operatorname{RMR}\left(\mathrm{kcal}^{\mathrm{d}} \mathrm{d}^{-1}\right)=\left[\left(3.941 \times \mathrm{VO}_{2}\right)+\left(1.1106 \times \mathrm{VCO}_{2}\right)\right] \times 1440$

$\mathrm{CHO}_{\text {ox }}\left(\mathrm{g} \cdot \mathrm{min}^{-1}\right)=\left[\left(4.585 \times \mathrm{VCO}_{2}\right)-\left(3.22255 \times \mathrm{VO}_{2}\right)\right]$

$\mathrm{FAT}_{\text {ox }}\left(\mathrm{g} \cdot \mathrm{min}^{-1}\right)=\left[\left(1.6946 \times \mathrm{VO}_{2}\right)-\left(1.7012 \times \mathrm{VCO}_{2}\right)\right]$

Gas exchanges were monitored during the $2 \mathrm{~h}$ recovery period. EE (kcal) was calculated every 30 minutes during the recovery period using the mean $\mathrm{VO}_{2}$ at that time point and the thermal coefficient of $\mathrm{O}_{2}$ corresponding to the recorded RER:

$\mathrm{EE}(\mathrm{kcal})=\mathrm{VO}_{2}\left(\mathrm{~L} \cdot \mathrm{min}^{-1}\right) \times$ time $(\min ) \times \mathrm{O}_{2}$ coef

$\mathrm{CHO}_{\text {ox }}$ and $\mathrm{FAT}_{\mathrm{ox}}\left(\mathrm{g} \cdot \mathrm{min}^{-1}\right)$ were calculated from the mean of the first 5 minutes of recovery and then at 20-30 $\mathrm{min}, 30-40 \mathrm{~min}, 40-50 \mathrm{~min}, 50-60 \mathrm{~min}, 60-70 \mathrm{~min}, 80-90 \mathrm{~min}, 90-100 \mathrm{~min}$, 100-110 min, and 110-120 min post-exercise. The total amount of oxidized $\mathrm{CHO}$ and fat (g) were calculated for each time point. 


\section{Glycaemia}

Fasting blood glucose concentration was measured directly from fingertip blood with an Accu-

Chek Performa meter (Roche Diabetes Care, France) before starting the exercise session, immediately post-exercise, and every 30 min during the recovery period.

\section{Physical Activity Enjoyment Scale (PACES) and Rate of Perceived Exertion (RPE)}

The PACES ${ }^{20}$ contains 18 items, and answers are rated on a 7-point bipolar Likert scale. After reverse scoring of the 11 items that are worded negatively, the total PACES score ranges between 18 and 126, and higher score indicates greater enjoyment. Participants completed the PACES immediately after the end of each exercise session.

The rate of perceived exertion was recorded using the CR-10 Scale ${ }^{21}$ at $25 \%, 50 \%, 75 \%$ and $100 \%$ of exercise completion.

\section{Appetite Rating and Breakfast Composition}

A validated 100-mm Visual Analogue Scale (VAS) ${ }^{22}$ was used to assess the subjective appetite at different time points: before exercise, immediately post-exercise, and during the recovery period (at the 60 and $120 \mathrm{~min}$ ). This scale includes four questions anchored with words that represent the two extreme states of desire to eat, hunger, fullness and prospective food consumption, as shown below.

(1) How strong is your desire to eat? ('very weak' to 'very strong'),

(2) How hungry do you feel? ('not hungry' to 'as hungry as I've ever felt'),

(3) How full do you feel? ('not full at all' to 'very full'), and

(4) How much food do you think you could eat? ('nothing at all' to 'a large amount').

The average appetite score was calculated using the following formula:

Appetite score $=($ desire to eat + hunger $+(100-$ fullness $)+$ prospective consumption $) / 4$ 
After the recovery period, participants were instructed to consume a standard breakfast (selected by the participant and the same for all three sessions) in 15 minutes. Breakfast included bread, butter, fruits and/or orange juice, dairy products, and infusion or decaffeinated coffee. With the help of a dietician, the breakfast had to reach $20-25 \%$ of the subject's daily total energy intake $\left(\sim\right.$ 2000-2200 kcal.day $\left.{ }^{-1}\right)$ and respect macronutrient repartition. The breakfast mean energy intake was $488 \pm 89 \mathrm{kcal}$ with $57 \%, 28 \%$ and $14 \%$ of $\mathrm{CHO}$, fat and proteins, respectively. As breakfast was late, it was advised to have lunch not before 1:00 PM.

\section{Dietary and physical activity assessments}

Participants were requested to fill in a food diary with the time and amount of food ingested from the dinner the day before the exercise session until the breakfast of the morning after exercise day. Total energy intake (kcal) and macronutrient intakes ( $\mathrm{CHO}$, fat \& proteins) were calculated using a nutrition analysis software (Nutrilog®, Marans, France).

The physical activity level of each participant was determined at baseline (the week before the first session) using the GPAQ ${ }^{17}$.

To assess the total energy expenditure $24 \mathrm{~h}$ after the exercise session, each participant completed a questionnaire to record her daily physical activity ${ }^{23}$. The estimated energy requirements were calculated from the calculated RMR, in addition to the EE for each physical activity. The energy balance was calculated using the following formula: Energy balance $=$ Total energy intake Total energy expenditure.

\section{Statistical Analyses}

Before the study starts, the sample size required was calculated based on excess post-exercise oxygen consumption (EPOC) following aerobic-type continuous and interval trainings from the 
study by Matsuo et al. ${ }^{24}$. For a statistical power of $80 \%, 10$ subjects per group were required to show a minimum EPOC difference of $3.2 \mathrm{~L}$ between the continuous $v s$. interval training for risks of error of $1^{\text {st }}$ (bilateral) and $2^{\text {nd }}$ species of $5 \%$. The sample was increased to 15 women to take into account participants lost to follow-up.

All statistical analyses were carried out with STATISTICA version 12.00 (StatSoft Inc., Tulsa, $\mathrm{OK})$. Data are presented as the mean $\pm \mathrm{SD}$. The data normal distribution was tested using the Kolmogorov-Smirnov test, and the homogeneity of variance was tested with the F-test. Data were log-transformed, when appropriate, before statistical analyses.

To compare a parameter in the three exercise modalities, Friedman's ANOVA (nonparametric test for paired samples) was performed, followed by the Wilcoxon test, if a significant effect was found. To compare the changes of a parameter over time and among the three modalities, two-way repeated-measures ANOVA was carried out to determine time and modality effects and time-modality interactions. When a significant effect was found, post-hoc multiple comparisons were performed using the Newman-Keuls method. The mean recovery values were also expressed as area under the curve (AUC) calculated with the trapezoidal method. In that case, a Friedman ANOVA was also used to establish differences among the three sessions. Differences with a P value $\leq 0.05$ were considered statistically significant.

\section{RESULTS}

\section{Participants' characteristics}

The mean age of the 12 postmenopausal women was $59.5 \pm 5.8$ years, and their mean weight, BMIbody mass index, waist circumference and fat mass percentage were $74.2 \pm 10.4 \mathrm{~kg}, 28.9$ $\pm 3.9 \mathrm{~kg} \cdot \mathrm{m}^{-2}, 99.6 \pm 9.4 \mathrm{~cm}$ and $39.2 \pm 5.1 \%$, respectively. 


\section{Exercise sessions}

No adverse event, such as pain or hypoglycaemia, was reported by participants during the three exercise sessions. Heart rate monitoring throughout the exercise sessions indicated a mean $\mathrm{HR}_{\max }$ percentage of $64.9 \pm 8.6 \%, 84.1 \pm 3.8 \%$, and $86.8 \pm 2.6 \%$ during the MICE, HIIE 1 and HIIE 2 session, respectively.

\section{$V O_{2}, R E R$ and $E E$}

No session effect was observed concerning RMR (mean value of $1306 \pm 167 \mathrm{kcal}^{\text {.day }}{ }^{-1}$ ). Baseline (at rest) $\mathrm{VO}_{2}\left(\mathrm{~L} \cdot \mathrm{min}^{-1}\right)$, RER and $\mathrm{EE}\left(\mathrm{kcal} . \mathrm{min}^{-1}\right)$ were not different before each exercise session: $0.18 \pm 0.02$ L. $\mathrm{min}^{-1}, 0.87 \pm 0.05$, and $1.02 \pm 0.43 \mathrm{kcal} . \mathrm{min}^{-1}$, respectively (Fig. 3). The three exercise modalities increased $\mathrm{VO}_{2}$ in the same range, as shown by the absence of exercise modality effect on deltaVO ${ }_{2}\left[\mathrm{VO}_{2}\right.$ immediately post-exercise $-\mathrm{VO}_{2}$ at baseline)/baseline $\left.\left.\mathrm{VO}_{2} \times 100\right] ; \mathrm{p}=0.24\right)$. However, delta RER tended to be lower after MICE $(\mathrm{p}=0.07)$. At 30 min post-exercise, the $\mathrm{VO}_{2}$ and $\mathrm{RER}$ values were different compared with the immediately post-exercise (IP) values $(\mathrm{p}<0.02)$, but not compared with the baseline values. Then, they remained constant until the end of the recovery period. Neither modality effect nor time $\times$ modality interaction was observed for $\mathrm{VO}_{2}$ and RER (Fig 3A and 3B). EE increased during the post-exercise period, without any difference among exercise modalities, and reached a total of $131 \pm 26 \mathrm{kcal}$ at the end of the post-exercise period (Fig. 3C).

\section{CHO \& Fat utilization}

The baseline $\mathrm{CHO}_{\mathrm{ox}}$ and $\mathrm{FAT}_{\mathrm{ox}}$ values, measured in fasting conditions, were comparable before each session: $0.13 \pm 0.04 \mathrm{~g} \cdot \mathrm{min}^{-1}$ and $0.04 \pm 0.02 \mathrm{~g} \cdot \mathrm{min}^{-1}$, corresponding to $55 \pm 17 \%$ and $45 \pm$ $17 \%$. Neither exercise modality effect nor modality $\times$ time interaction was observed concerning 
the post-exercise $\mathrm{CHO}_{\text {ox }}$ and $\mathrm{FAT}_{\mathrm{ox}}$ values (expressed in g.min ${ }^{-1}$ or in percentage) (Fig. 4). $\mathrm{CHO}_{\text {ox }}\left(\right.$ g. $\left.\mathrm{min}^{-1}\right)$ was significantly higher immediately post-exercise compared with baseline (time effect, $\mathrm{p}<0.0002$ ). The recovery period (compared with immediately post-exercise) induced a shift on substrate utilization, leading to greater $\mathrm{FAT}_{\mathrm{ox}}$ and lower $\mathrm{CHO}_{\mathrm{ox}}\left(\mathrm{g} \cdot \mathrm{min}^{-1}\right.$ and percentage $)(\mathrm{p}<0.02)$.

\section{Enjoyment and perceived exertion}

The immediately post-exercise PACES scores indicated no significant difference in enjoyment among the three modalities $(91.3 \pm 15.4,90.8 \pm 17.0$ and $86.8 \pm 10.9$, for MICE, HIIE 1 and HIIE 2, respectively; $\mathrm{p}=0.76$ ) (data not shown). The rate of perceived exertion (measured at 25, 50,75 and $100 \%$ of exercise completion) increased during exercise (time effect, $\mathrm{p}<10^{-4}$ ), but were lower for MICE than for HIIE $1 \& 2$ (group effect, $\mathrm{p}<10^{-4}$ ). When expressed as area under the curve, the rates of perceived exertion values were lower during MICE than HIIE 1 and HIIE $2(\mathrm{p}<0.05)($ Fig. 5).

\section{Perception of appetite}

Analysis of the perceived appetite scores (Fig. 6) showed a significant time effect $\left(\mathrm{p}<10^{-4}\right)$, without exercise modality effect $(p=0.17)$. A modality $\times$ time interaction appeared at $60 \mathrm{~min}$ post-exercise, with higher perceived appetite scores after MICE than after HIIE 1 ( $p=0.007)$ and HIIE $2(\mathrm{p}=0.03)$. When expressed as AUC, a modality effect was observed, with higher perceived appetite score for MICE than HIIE 1 ( $\mathrm{p}=0.026)$ and HIIE 2 (p=0.041) (Fig. 6).

All four appetite sub-scores (desire to eat, hunger, fullness, and prospective food consumption) showed a significant time effect $(p<0.0001)$, but no exercise modality effect ( $p>0.05)$ (Fig. 7). A modality $\times$ time interaction was observed for hunger and prospective food consumption at 60 min post-exercise, with higher values after MICE than HIIE 1 and HIIE $2(p<0.02)$. When 
expressed as AUC, the hunger and prospective food consumption sub-scores were higher in MICE than in HIIE $1(\mathrm{p}<0.02)$.

\section{Glycaemia measurements}

Baseline glycaemia in fasting conditions was comparable before all three sessions $(0.96 \pm 0.11$ g. $\left.\mathrm{L}^{-1}\right)$. Glycaemia was not affected by the exercise modality and was not modified during the recovery period (time and modality effect; $\mathrm{p}>0.05$ ). Similarly, no modality $\times$ time interaction was noted (data not shown).

\section{4 post-exercise energy intake and energy expenditure}

The energy (kcal) consumed the night before each exercise session was comparable for all three sessions $(480 \pm 133 \mathrm{kcal})$. The $24 \mathrm{~h}$ post-exercise period covered the time from the end of breakfast after the exercise session to the same hour the next day. Table 1 shows the $24 \mathrm{~h}$ postexercise energy intake, including the three meals (lunch, dinner and breakfast), the percentage of $\mathrm{CHO}$, fat and proteins consumed during the $24 \mathrm{~h}(\% 24 \mathrm{~h}$ post-exercise energy intake), the $24 \mathrm{~h}$ post-exercise energy expenditure, and the energy balance. No modality effect was noted for all these parameters. Overall, the three exercise sessions did not induce any specific adaptation concerning diet and physical activity level.

\section{DISCUSSION}

The aim of this study was to determine whether differences in the acute effect of three exercise modalities (one MICE and two HIIE) on 2h post-exercise $\mathrm{VO}_{2}$, fat utilization, appetite, and 24h-post-exercise EI and EE could explain the higher fat mass reduction observed in 
postmenopausal women after HIIT compared with MICT. Our data indicate that $\mathrm{VO}_{2}$ and fat utilization during the $2 \mathrm{~h}$ of recovery were comparable for all three-exercise modalities. The three modalities also induced similar $24 \mathrm{~h}$ EI and EE, despite the short (1h) post-exercise anorexigenic effect of HIIE $1 \& 2$. The perceived exertion was lower with MICE, but enjoyment did not differ among modalities.

Our group already demonstrated that HIIT is a time-efficient and safe exercise modality for loosing total and (intra-)abdominal fat mass in postmenopausal women ${ }^{10-12}$. However, the mechanisms leading to a greater fat mass loss in HIIT vs MICT are still unclear. HIIE stimulates catecholamine production leading to lipolysis and higher post-exercise free fatty acid availability ${ }^{9}$. Fat oxidation could be facilitated by a higher oxygen consumption observed after exercises performed at an intensity above $75 \%$ of $\mathrm{VO}_{2 \max }{ }^{14,15}$. Therefore, using a randomized crossover design, we compared the $2 \mathrm{~h}$ post-exercise $\mathrm{VO}_{2}$ and fat utilization after three isoenergetic exercise sessions (MICE, and two HIIE with different active phase duration but at the same intensity). The first one $\left[60 \times(8 \mathrm{~s}\right.$ cycling -12 s recovery $)$ at $\left.80-90 \% \mathrm{HR}_{\max }\right]$ has been extensively tested by our group and by others in pre- and post-menopausal women ${ }^{10-12,25}$ The second one $\left[10 \times 1 \mathrm{~min}\right.$ at $80-90 \% \mathrm{HR}_{\max }-1 \mathrm{~min}$ recovery $]$ is regularly used in different population types (i.e. normal weight, overweight, obese people, young or older, trained or untrained subjects) ${ }^{26-28}$. We hypothesized that for the same exercise duration, the longer active phase of HIIE (10min for HIIE 2 vs 8 min for HIIE 1) could induce greater post-exercise $\mathrm{VO}_{2}$ uptake and/or fat utilization. However, our results showed no difference in post-exercise $\mathrm{VO}_{2}$ and fat utilization among the three exercise modalities. In all conditions, $\mathrm{VO}_{2}$ and $\mathrm{FAT}_{\mathrm{ox}}$ rates reached resting values at 30 min post-exercise and remained constant until the end of the $2 \mathrm{~h}$ recovery period. It has been reported that the relationship between excess post-exercise oxygen consumption (EPOC) magnitude and the exercise bout intensity is curvilinear, whereas the relationship between EPOC magnitude and exercise duration is more linear, especially at higher 
intensities ${ }^{14}$. In this context, our study did not demonstrate the hypothesis that compared with MICE, HIIE induces higher $\mathrm{VO}_{2}$ consumption due to the higher intensities reached. In agreement, among the eight studies on HIIE and MICE effect on EPOC within 0.5-3h postexercise, only three reported a significant effect of HIIE on post-exercise $\mathrm{VO}_{2}{ }^{26,29,30}$, whereas the others did not find any difference between modalities ${ }^{24,31-34}$. These discrepancies are probably linked to the fact that these studies were performed in different populations (young, old, healthy, not healthy, trained, untrained, men, women) and using different HIIE and MICE protocols (intensity, duration, ergometer used). In our protocol, the three sessions led to similar caloric expenditure. On the other hand, our study was the first in postmenopausal women whose specific hormonal status may alter post-exercise $\mathrm{VO}_{2}{ }^{14}$. High EPOC is in part linked to increased circulation, ventilation and body temperature, but the cost of this is low ${ }^{14}$. An increased rate of triglyceride/fatty acid cycling and a shift from carbohydrate to fat as substrate source might contribute to EPOC after high-intensity exercises ${ }^{14}$. In our study, fat utilization was increased during the recovery period, but without a significant exercise modality effect. In fact, all three sessions increased carbohydrate oxidation during exercise (as shown by the higher values immediately post-exercise than at rest), whereas MICE did not significantly increase fat oxidation during exercise. We hypothesize that the MICE session duration was too short for stimulating $\beta$-oxidation and importantly, that in such deconditioned subjects, exercise intensity was too high to shift significantly towards fat utilization. Thus, although the HIIE sessions were performed at a higher intensity $(+30 \%)$, the fact that MICE largely favoured carbohydrate use during an exercise of longer duration ( $+75 \%)$ could mask post-exercise fat oxidation differences and also contribute to explain the similar EPOC among exercise modalities. Moreover, at the same intensity, the longer active phase of HIIE 2 (compared with HIIE 1) was not sufficient to induce greater post-exercise $\mathrm{VO}_{2}$ and fat utilization. 
Alternatively the higher fat mass reduction observed in postmenopausal women after HIIT compared with MICT ${ }^{10-12}$ could be explained by an increase of the total daily energy expenditure and/or by the appetite suppressive effects after HIIE ${ }^{35}$. Indeed, it has been shown that acute HIIE stimulates anorexigenic signals that could reduce energy intake for few hours 16. However, comparison of HIIE and MICE effects on short term post-exercise perceived appetite showed higher ${ }^{36}$, similar ${ }^{16}$ or no reduction ${ }^{37}$ of the appetite score by HIIE. In our study, the perceived appetite score during the $2 \mathrm{~h}$ recovery period (AUC data) was lower after HIIE $1 \& 2$ than MICE. However, when results were analysed over time, the difference was significant (appetite score and also hunger and prospective food consumption sub-scores) only at $1 \mathrm{~h}$ post-exercise. These findings suggest that acute isoenergetic HIIE and MICE sessions may differently affect the post-exercise perceived appetite in fasted postmenopausal women. In our study, we decided to start each session in fasting conditions and to give a standard breakfast after the $2 \mathrm{~h}$-recovery period in order to normalize pre- and post-session energy status. However, the standard breakfast did not allow us to confirm the acute anorexigenic effect of HIIE. Nevertheless, we think that this effect is temporary because we did not detect any specific HIIE effect on the amount of macronutrient consumed (in total and in each meal) during the $24 \mathrm{~h}$ postexercise. This was already observed in men with obesity ${ }^{38}$ who showed similar $24 \mathrm{~h}$ energy intake after HIIE $\left(10 \times 1\right.$ - min at $85-90 \% \mathrm{HR}_{\max }$ with 1 -min recovery) and MICE (20-min at 65$70 \% \mathrm{HR}_{\max }$ ), despite an apparent transient reduction in hunger immediately after HIIE. Energy expenditure during the $24 \mathrm{~h}$ post-exercise period is rarely measured. In our study, the $24 \mathrm{~h}$ energy expenditure was comparable among exercise modalities. In conclusion, our results show that despite a short (1h) post-exercise anorexigenic effect of HIIE $1 \& 2$, the 24 h energy intake \& expenditure were comparable among modalities, leading to similar energy balance.

The rate of perceived exertion during exercise and enjoyment may have an important role for improving adoption and adherence to the prescribed exercise programs, particularly in 
individuals with overweight/obesity ${ }^{39}$. Literature data suggest higher enjoyment after HIIE than MICE due to the shorter time commitment and the challenge ${ }^{13,39}$. In our study, the rate of perceived exertion increased throughout exercise, but was higher during HIIE $1 \& 2$ than MICE. Besides the muscle constraints generated by HIIE (higher velocity and intensity performed), the fact that women performed the sessions in fasting conditions could have made HIIE more difficult, due to higher glycogen and plasma glucose utilization ${ }^{40}$. However, we did not find any effect of HIIE or MICE on glycaemia during or after exercise. Finally, despite higher rates of perceived exertion in HIIE $1 \& 2$ vs. MICE, enjoyment was similar for all three modalities, thus confirming the feasibility of such programmes in this population.

\section{Limitations}

The most important limitation of this study is that we used results obtained during acute exercise sessions (HIIE and MICE) to explain chronic effects (HIIT and MICT adaptations). It would have been interesting to analyse the same parameters after 2-3 months of training. However, inter-subject variability could strongly influence the results. In our study, we took care to match the exercise session in terms of EE and to avoid any difference in energy status before each session by starting in fasting conditions. This could be perceived as a limitation because it does not reflect the "true life", but allowed us to accurately compare post-exercise $\mathrm{VO}_{2}$ and substrate oxidation. Finally, the last limitation concerns the questionnaires used (VAS, PACES, food intake, energy expenditure) due to their subjectivity and/or the difficulty to perfectly estimate EI and EE. However, as the same participants performed the three sessions, there is no reason to imagine that differences occurred from a session to the other. 


\section{PERSPECTIVE}

The present study showed that in postmenopausal women, when exercise sessions are matched for caloric expenditure, the $2 \mathrm{~h}$ post-exercise $\mathrm{VO}_{2}$ and fat utilization are similar with HIIE and MICE. Longer (24h) post-exercise $\mathrm{VO}_{2}$ and substrate utilization measurements might be

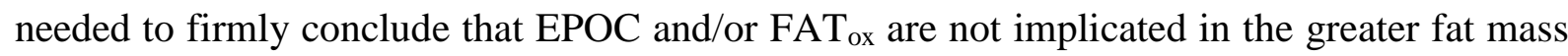
loss observed after HIIT. Similarly, HIIT-induced higher fat mass reduction cannot be explained by a modulation of the $24 \mathrm{~h}$ EE and EI. Additional studies are needed to determine whether long-term exercise could alter these acute responses. Nevertheless, our study confirms that HIIE and MICE are well tolerated by postmenopausal women, are safe, and may induce the same level of enjoyment. Therefore, each of them can be proposed for obesity management, in consultation with the patients to improve long-term practice adherence.

\section{Acknowledgments}

The authors wish to thank all the study participants for their kind collaboration. The authors declare that they have no competing interests.

\section{Financial support}

The Study was funded by the University of Clermont Auvergne (AME2P laboratory). The funders had no role in the study design, the collection, analysis, and interpretation of data, the writing of the manuscript, and the decision to submit the article for publication. 


\section{References}

1. Palmer BF, Clegg DJ. The sexual dimorphism of obesity. Mol Cell Endocrinol 2015;402:113-119.

2. Poehlman ET. Menopause, energy expenditure, and body composition. Acta Obstet Gynecol Scand 2002;84:1131.

3. Gavin KM, Kohrt WM, Klemm DJ, Melanson EL. Modulation of Energy Expenditure by Estrogens and Exercise in Women. Exerc Sport Sci Rev 2018;46:232-239.

4. Walecka-Kapica E, Chojnacki J, Stępień A, Wachowska-Kelly P, Klupińska G, Chojnacki C. Melatonin and female hormone secretion in postmenopausal overweight women. Int $\mathrm{J}$ Mol Sci 2015;16:1030-1042.

5. Karvonen-Gutierrez C, Kim C. Association of Mid-Life Changes in Body Size, Body Composition and Obesity Status with the Menopausal Transition. Healthc Basel Switz 2016;4:42.

6. Thompson PD, Arena R, Riebe D, Pescatello LS. ACSM's New Preparticipation Health Screening Recommendations from ACSM's Guidelines for Exercise Testing and Prescription, Ninth Edition. Curr Sports Med Rep 2013;12:215-217.

7. Frank LL, Sorensen BE, Yasui Y, Tworoger SS, Schwartz RS, Ulrich CM, Irwin ML, Rudolph RE, Rajan KB, Stanczyk F, Bowen D, Weigle DS, Potter JD, McTiernan A. Effects of exercise on metabolic risk variables in overweight postmenopausal women: a randomized clinical trial. Obes Res 2005;13:615-625.

8. Zhang H, Tong TK, Qiu W, Zhang X, Zhou S, Liu Y, He Y. Comparable Effects of HighIntensity Interval Training and Prolonged Continuous Exercise Training on Abdominal Visceral Fat Reduction in Obese Young Women. J Diabetes Res 2017;2017:5071740.

9. Maillard F, Pereira B, Boisseau N. Effect of High-Intensity Interval Training on Total, Abdominal and Visceral Fat Mass: A Meta-Analysis. Sports Med 2018;48:269-288.

10. Dupuit M, Rance M, Morel C, Bouillon P, Pereira B, Bonnet A, Maillard F, Duclos M, Boisseau N. Moderate-Intensity Continuous Training or High-Intensity Interval Training with or without Resistance Training for Altering Body Composition in Postmenopausal Women. Med Sci Sports Exerc 2020;52:736-745.

11. Maillard F, Rousset S, Pereira B, Traore A, de Pradel Del Amaze P, Boirie Y, Duclos M, Boisseau N. High-intensity interval training reduces abdominal fat mass in postmenopausal women with type 2 diabetes. Diabetes Metab 2016;42:433-441.

12. Maillard F, Rousset S, Pereira B, Boirie Y, Duclos M, Boisseau N. High-intensity interval training is more effective than moderate-intensity continuous training in reducing abdominal fat mass in postmenopausal women with type 2 diabetes: A randomized crossover study. Diabetes Metab 2018;44:516-517. 
13. Thum JS, Parsons G, Whittle T, Astorino TA. High-Intensity Interval Training Elicits Higher Enjoyment than Moderate Intensity Continuous Exercise. PloS One 2017;12:e0166299.

14. Børsheim E, Bahr R. Effect of Exercise Intensity, Duration and Mode on Post-Exercise Oxygen Consumption. Sports Med 2003;33:1037-1060.

15. Moniz SC, Islam H, Hazell TJ. Mechanistic and methodological perspectives on the impact of intense interval training on post-exercise metabolism. Scand J Med Sci Sports 2020;30:638-651.

16. Sim AY, Wallman KE, Fairchild TJ, Guelfi KJ. High-intensity intermittent exercise attenuates ad-libitum energy intake. Int J Obes 2014;38:417-422.

17. Hallal PC, Andersen LB, Bull FC, Guthold R, Haskell W, Ekelund U. Global physical activity levels: surveillance progress, pitfalls, and prospects. The Lancet 2012;380:247257.

18. Tanaka H, Monahan KD, Seals DR. Age-predicted maximal heart rate revisited. J Am Coll Cardiol 2001;37:153-156.

19. Péronnet F, Massicotte D. Table of nonprotein respiratory quotient: an update. Can J Sport Sci J Can Sci Sport 1991;16:23-29.

20. Kendzierski D, DeCarlo KJ. Physical Activity Enjoyment Scale: Two Validation Studies. J Sport Exerc Psychol 1991;13:50-64.

21. Borg G. Borg's perceived exertion and pain scales. Champaign, IL, US: Human Kinetics; 1998. viii, $104 \mathrm{p}$.

22. Flint A, Raben A, Blundell JE, Astrup A. Reproducibility, power and validity of visual analogue scales in assessment of appetite sensations in single test meal studies. Int J Obes 2000;24:38-48.

23. Pereira MA, FitzerGerald SJ, Gregg EW, Joswiak ML, Ryan WJ, Suminski RR, Utter AC, Zmuda JM. A collection of Physical Activity Questionnaires for health-related research. Med Sci Sports Exerc 1997;29:S1-205.

24. Matsuo T, Ohkawara K, Seino S, Shimojo N, Yamada S, Ohshima H, Tanaka K, Mukai C. Cardiorespiratory fitness level correlates inversely with excess post-exercise oxygen consumption after aerobic-type interval training. BMC Res Notes 2012;5:646.

25. Trapp EG, Chisholm DJ, Freund J, Boutcher SH. The effects of high-intensity intermittent exercise training on fat loss and fasting insulin levels of young women. Int $\mathbf{J}$ Obes 2008;32:684-691.

26. Wingfield HL, Smith-Ryan AE, Melvin MN, Roelofs EJ, Trexler ET, Hackney AC, Weaver MA, Ryan ED. The acute effect of exercise modality and nutrition manipulations on post-exercise resting energy expenditure and respiratory exchange ratio in women: a randomized trial. Sports Med - Open 2015;1:11. 
27. Berger NJA, Tolfrey K, Williams AG, Jones AM. Influence of Continuous and Interval Training on Oxygen Uptake On-Kinetics. Med Sci Sports Exerc 2006;38:504-512.

28. Sawyer BJ, Tucker WJ, Bhammar DM, Ryder JR, Sweazea KL, Gaesser GA. Effects of high-intensity interval training and moderate-intensity continuous training on endothelial function and cardiometabolic risk markers in obese adults. J Appl Physiol Bethesda Md 1985 2016;121:279-288.

29. Treuth MS, Hunter GR, Kekes-Szabo T, Weinsier RL, Goran MI, Berland L. Reduction in intra-abdominal adipose tissue after strength training in older women. $\mathbf{J}$ Appl Physiol 1995;78:1425-1431.

30. Karstoft K, Wallis GA, Pedersen BK, Solomon TPJ. The effects of interval- vs. continuous exercise on excess post-exercise oxygen consumption and substrate oxidation rates in subjects with type 2 diabetes. Metabolism 2016;65:1316-1325.

31. Larsen I, Welde B, Martins C, Tjønna AE. High- and moderate-intensity aerobic exercise and excess post-exercise oxygen consumption in men with metabolic syndrome. Scand $\mathbf{J}$ Med Sci Sports 2014;24:e174-e179.

32. Tucker WJ, Angadi SS, Gaesser GA. Excess Postexercise Oxygen Consumption After High-Intensity and Sprint Interval Exercise, and Continuous Steady-State Exercise. J Strength Cond Res 2016;30:3090-3097.

33. McGarvey W, Jones R, Petersen S. Excess post-exercise oxygen consumption following continuous and interval cycling exercise. Int J Sport Nutr Exerc Metab 2005;15:28-37.

34. Warren A, Howden EJ, Williams AD, Fell JW, Johnson NA. Postexercise Fat Oxidation: Effect of Exercise Duration, Intensity, and Modality. Int J Sport Nutr Exerc Metab 2009;19:607-623.

35. Poon ETC, Sun FH, Chung APW, Wong SHS. Post-Exercise Appetite and Ad Libitum Energy Intake in Response to High-Intensity Interval Training versus Moderate- or Vigorous-Intensity Continuous Training among Physically Inactive Middle-Aged Adults. Nutrients 2018;10:1408.

36. Charlot K, Chapelot D. Comparison of energy-matched high-intensity interval and moderate-intensity continuous exercise sessions on latency to eat, energy intake, and appetite. Appl Physiol Nutr Metab 2018;44:665-673.

37. Deighton K, Karra E, Batterham RL, Stensel DJ. Appetite, energy intake, and PYY3-36 responses to energy-matched continuous exercise and submaximal high-intensity exercise. Appl Physiol Nutr Metab 2013;38:947-952.

38. De Matos MA, Vieira DV, Pinhal KC, Lopes JF, Dias-Peixoto M.F., Pauli J.R., De Castro Magalhães F., Little J.P., Rocha-Vieira E., Amorim F.T. High-intensity interval training improves markers of oxidative metabolism in skeletal muscle of individuals with obesity and insulin resistance. Front Physiol 2018;9:1451.

39. Oliveira BRR, Santos TM, Kilpatrick M, Pires FO, Deslandes AC. Affective and enjoyment responses in high intensity interval training and continuous training: A systematic review and meta-analysis. PloS One 2018;13:e0197124. 
40. Kong Z, Hu M, Liu Y, Shi Q, Zou L, Sun S, Zhang H, Nie J. Affective and Enjoyment Responses to Short-Term High-Intensity Interval Training with Low-Carbohydrate Diet in Overweight Young Women. Nutrients 2020;12:442. 
Table 1. Acute 24h-Energy Intake (EI) and Energy Expenditure (EE) after MICE, HIIE 1 and HIIE 2.

\begin{tabular}{|c|c|c|c|c|}
\hline & MICE & HIIE1 & HIIE2 & $\begin{array}{c}\mathbf{P} \\
\text { (Modality effect) }\end{array}$ \\
\hline 24h-El (kcal) & $1543 \pm 125$ & $1350 \pm 2218$ & $1542 \pm 190$ & 0.12 \\
\hline Lunch (kcal) & $631 \pm 206$ & $572 \pm 140$ & $615 \pm 165$ & 0.75 \\
\hline Dinner (kcal) & $577 \pm 214$ & $476 \pm 157$ & $568 \pm 296$ & 0.17 \\
\hline Breakfast (kcal) & $314 \pm 167$ & $280 \pm 133$ & $308 \pm 173$ & 0.38 \\
\hline $\mathrm{CHO}(\% 24 \mathrm{~h}-\mathrm{El})$ & $45 \pm 6$ & $46 \pm 7$ & $46 \pm 9$ & 0.46 \\
\hline FAT (\% 24h-EI) & $38 \pm 6$ & $34 \pm 8$ & $34 \pm 7$ & 0.36 \\
\hline Proteins (\% 24h-EI) & $16 \pm 4$ & $20 \pm 8$ & $20 \pm 5$ & 0.12 \\
\hline 24h-EE (Kcal) & $1815 \pm 329$ & $1893 \pm 288$ & $1900 \pm 274$ & 0.21 \\
\hline Energy Balance & $-302 \pm 385$ & $-491 \pm 284$ & $-378 \pm 229$ & 0.88 \\
\hline
\end{tabular}

MICE: Moderate-Intensity Continuous Training; HIIE 1: High-Intensity Intermittent Exercise 1; HIIE 2: High-Intensity Intermittent Exercise 2. 


\section{Figure legends}

\section{Fig. 1: Description of the exercise sessions.}

After inclusion (consultation and anthropometric/body composition measurements), each woman tried the three exercise modalities (one session/modality) at an interval of 6-8 days between modalities. MICE: Moderate Intensity Continuous Exercise; HIIE 1: High Intensity Intermittent Exercise 1; HIIE 2: High Intensity Intermittent Exercise 2; HR $\mathrm{max}_{\text {ax }}$ Maximal Heart Rate; rpm: Revolution Per Minute.

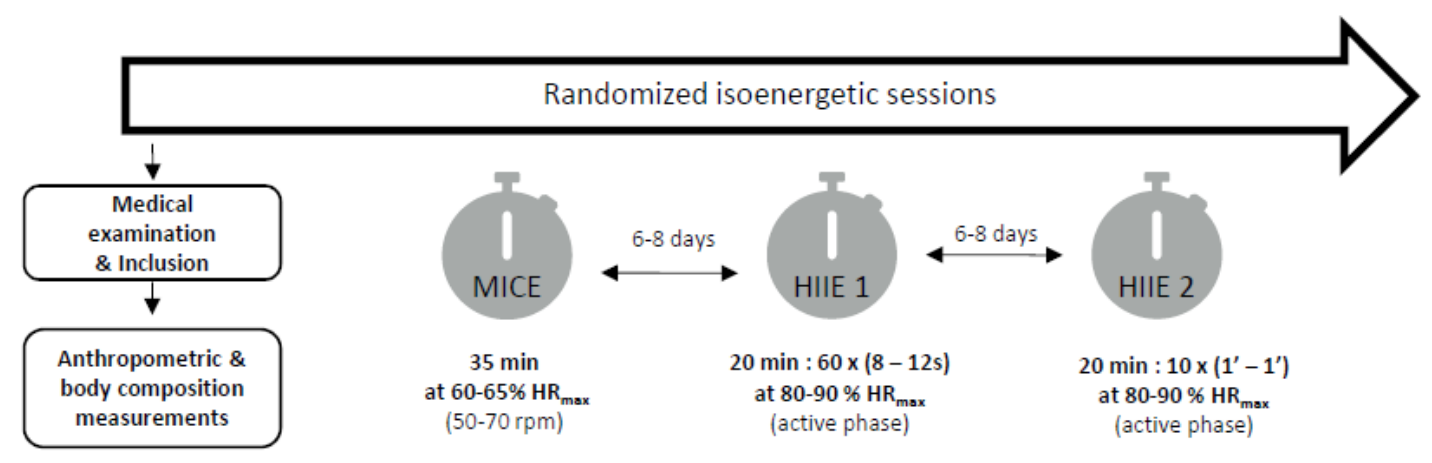


Fig. 2: Experimental Design

$\mathrm{CHO}_{\text {ox: }}$ Carbohydrate oxidation; FAT ox: Fat oxidation; EE: Energy Expenditure; IP: immediately post-exercise; PA: Physical Activity; PACES: Physical Activity Enjoyment Scale; RMR: Resting Metabolic Rate; RPE: Rate of Perceived Exertion; VAS: Visual Analogue Scale (subjective appetite).

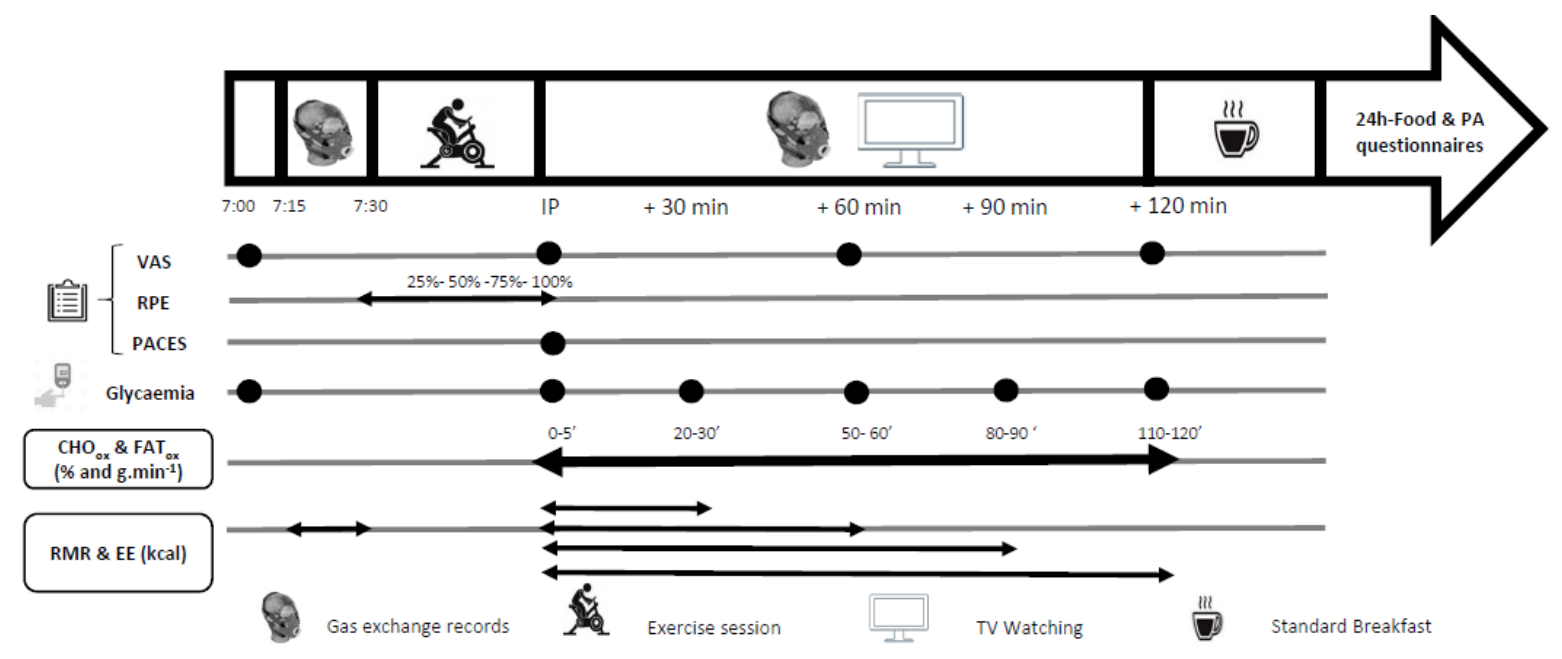


Fig. 3: Oxygen consumption $\left(\mathrm{VO}_{2}\right)(\mathrm{A})$ and Respiratory Exchange Ratio (RER) (B) at rest (baseline), immediately post-exercise (IP) and at 30, 60, 90, and 120 minutes of recovery. Post-exercise energy expenditure $(\mathrm{EE})$ at 30, 60, 90, and 120 minutes of recovery $(\mathrm{C})$ according to the exercise modality.

MICE: Moderate-Intensity Continuous Training; HIIE 1: High-Intensity Intermittent Exercise 1; HIIE 2: High-Intensity Intermittent Exercise 2. ${ }^{*} \mathrm{p}<0.05$ : time effect (IP $v s$ rest); $\delta \mathrm{p}<0.05$ : time effect (IP $v s$ recovery). 

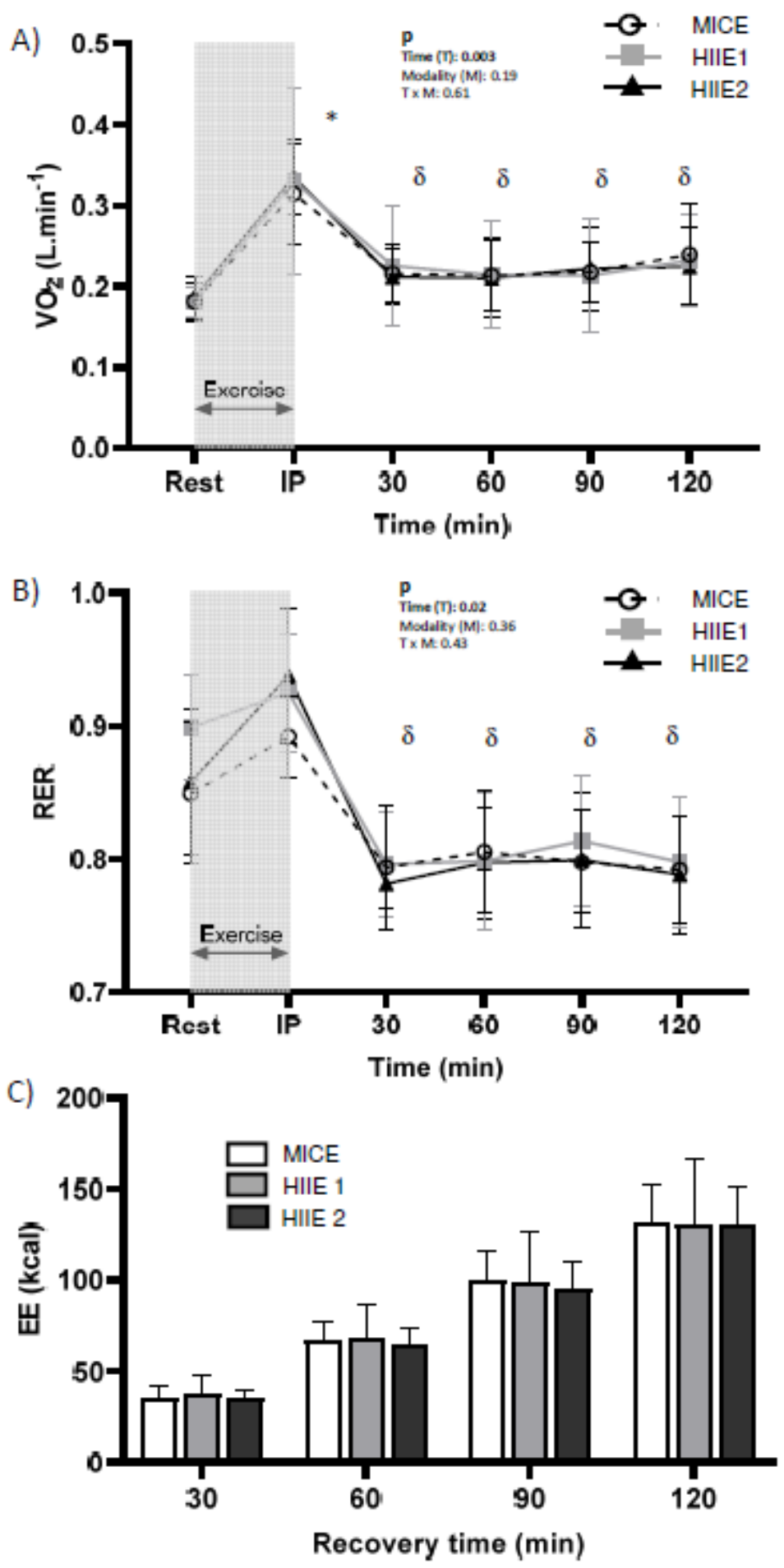
Fig. 4: Fat and carbohydrate (CHO) oxidation (g.min-1 and \%) at rest, immediately postexercise, and at 30, 60, 90, 120 minutes of recovery and for the entire recovery period (2h). IP: Immediately post-exercise; MICE: Moderate-Intensity Continuous Training; HIIE 1: HighIntensity Intermittent Exercise 1; HIIE 2: High-Intensity Intermittent Exercise 2; $*$ p <0.05: time effect (IP $v s$ rest) for $\mathrm{CHO} ; \delta \mathrm{p}<0.05$ : time effect (IP $v s$ recovery) for $\mathrm{CHO} ; \theta$ : time effect (rest $v s$ 120min of recovery) for $\mathrm{FAT}_{\text {ox. }} \gamma \mathrm{p}<0.05$ : time effect (IP vs recovery values) for $\mathrm{CHO}_{\mathrm{ox}}$ and FAT $_{\text {ox }}$

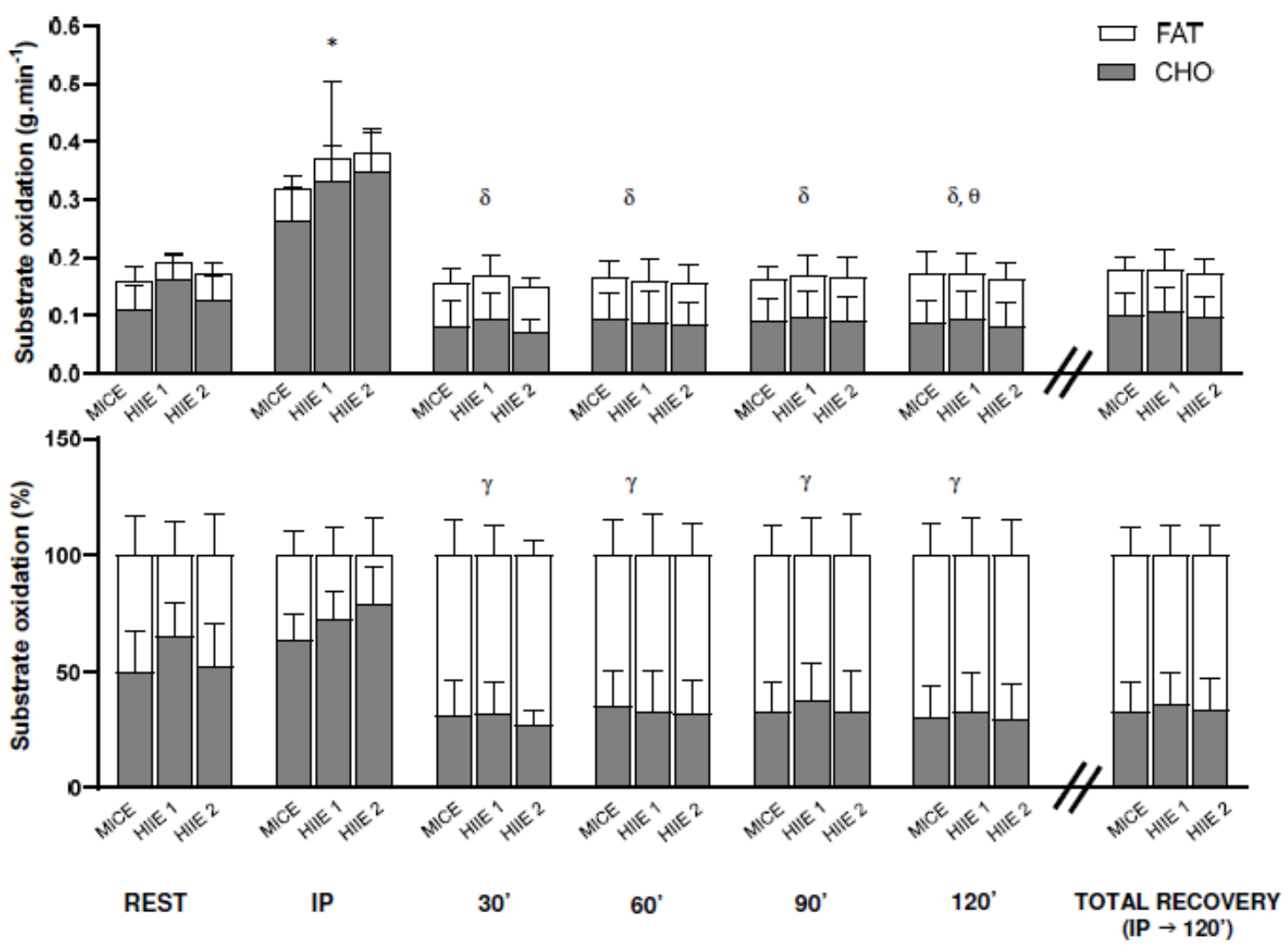


Fig. 5: RPE at rest (baseline) and at 25, 50, 75 and $100 \%$ of the exercise session completion.

RPE: rate of Perceived Exertion; MICE: Moderate-Intensity Continuous Training; HIIE 1:

High-Intensity Intermittent Exercise 1; HIIE 2: High-Intensity Intermittent Exercise 2.

* p<0.05: MICE vs HIIE 1 and HIIE 2.

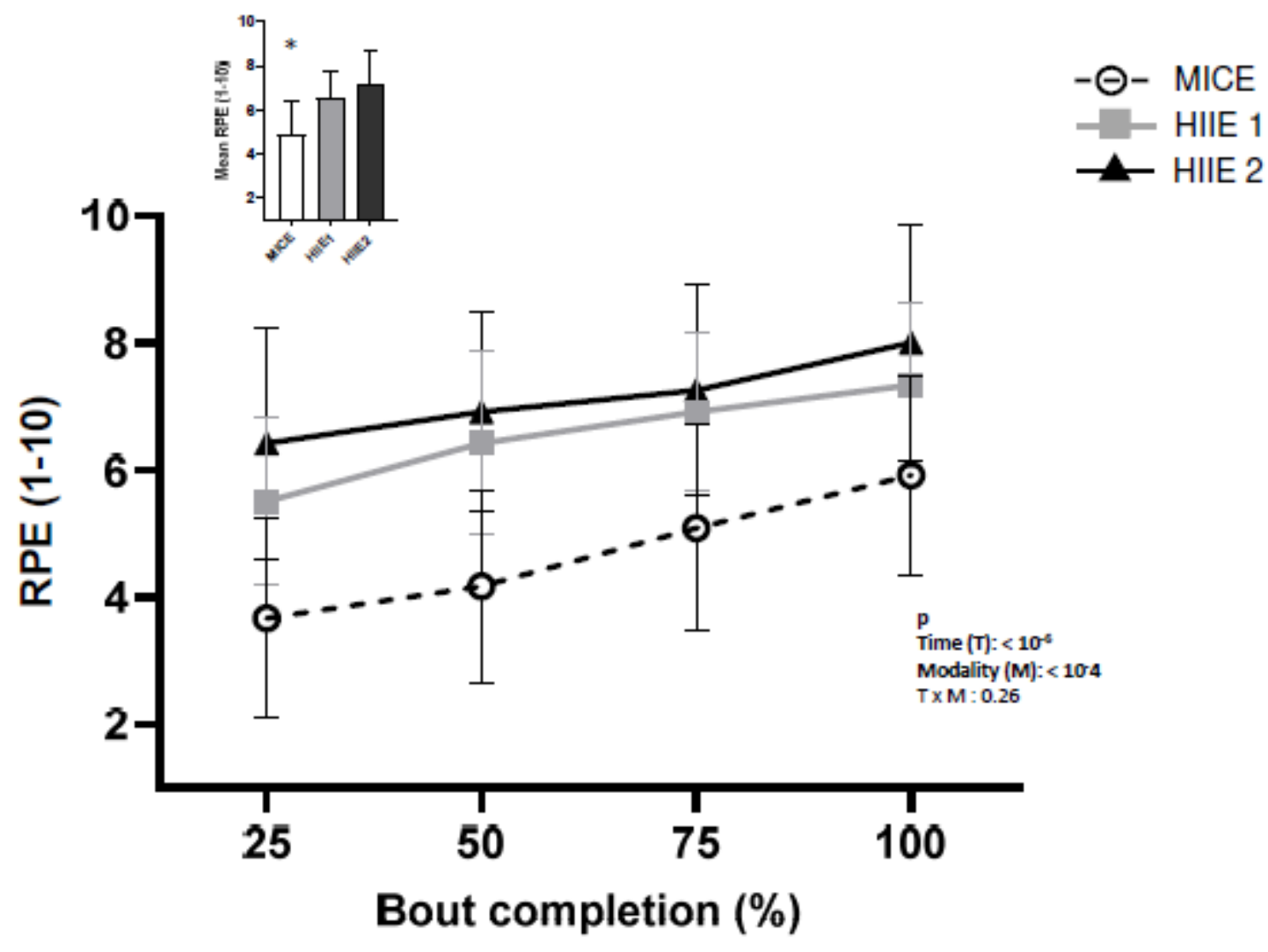


Fig. 6: Appetite score before exercise, immediately post-exercise and at 60 and the 120 minutes of recovery.

PRE: pre-exercise; IP: immediately post-exercise; MICE: Moderate-Intensity Continuous Training; HIIE 1: High-Intensity Intermittent Exercise 1; HIIE 2: High-Intensity Intermittent Exercise 2.

* p<0.05: MICE vs HIIE 1 and HIIE 2.

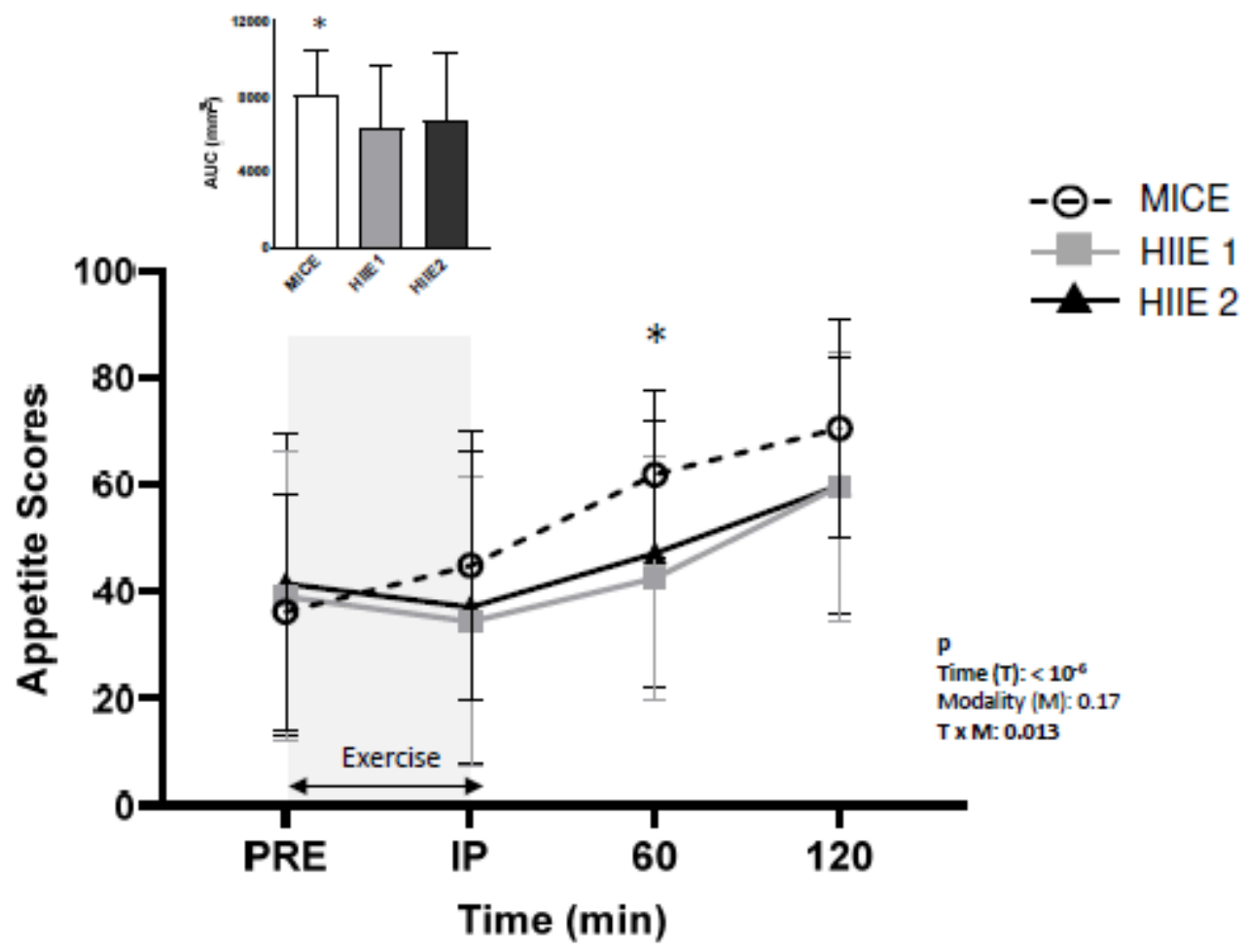


Fig. 7: VAS score for Hunger (A), Fullness (B), Desire to eat (C), Prospective Food Consumption (D) before, immediately after exercise, and at $1 \mathrm{~h}$ and $2 \mathrm{~h}$ post- exercise.

PFC: Prospective Food Consumption; PRE: pre-exercise; IP: immediately post-exercise; MICE: Moderate-Intensity Continuous Training; HIIE 1: High-Intensity Intermittent Exercise 1; HIIE 2: High-Intensity Intermittent Exercise 2.

* p<0.05: MICE vs HIIE 1 and HIIE 2; \# p<0.05: MICE vs HIIE1.
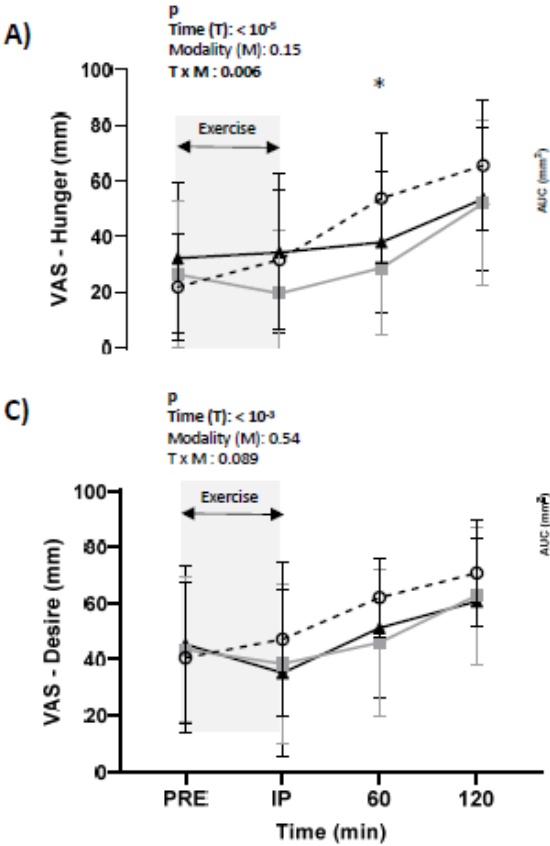
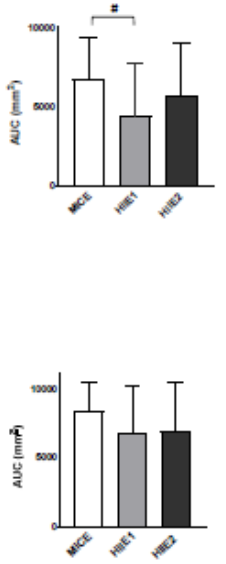

$\rightarrow-\mathrm{MICE}$

HIIE 1
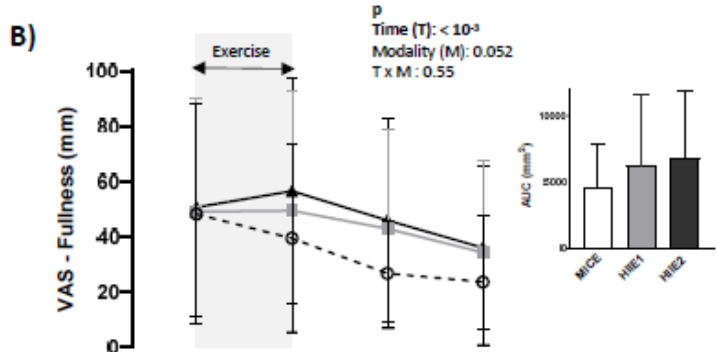

D)

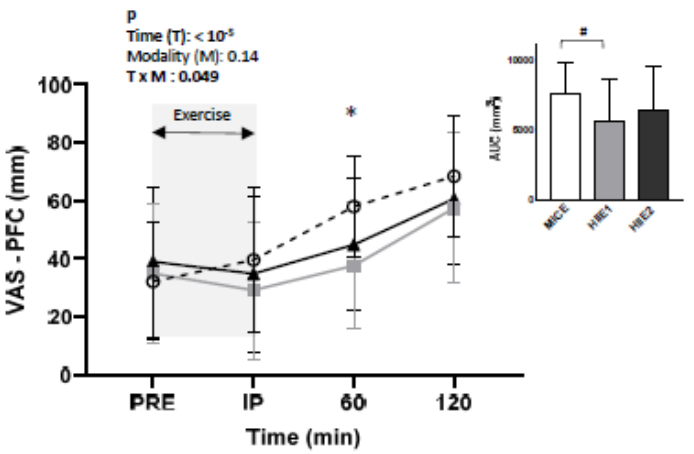

